\title{
Tracing Strategic Preferences in Cyberspace: The Role of Regional and Domestic Strategic Culture
}

\author{
Miguel Alberto Gomez
}

This article has been accepted for publication in Comparative Strategy, published by

Taylor \& Francis.

Our understanding of strategic preferences in cyberspace rests on the material and strategic factors that shape state behavior. This, however, is derived from the actions of established cyber powers. Given the material resources required to effectively operate in this environment and repeated interactions that form the boundaries of accepted behavior, the literature does not adequately explain the emergence of strategic preferences among novice actors. The article posits that these are not exclusively the function of either the material or strategic factors. Instead, strategic culture features prominently in the selection of strategic preferences that shape state behavior in cyberspace.

Keywords: cybersecurity; strategy; preferences; strategic culture 


\section{Introduction}

In 2016, ASEAN defense ministers approved the establishment of the ASEAN Defense Ministers Meeting Plus Cybersecurity Expert Working Group (ADMMP-CEWG). Acknowledging the risks posed to regional peace and stability, the ADMMP-CEWG represents an attempt by the regional body to depict cybersecurity as a vital component of national security (Parameswaran 2016). Ongoing rivalries and material disparity fit the narrative that the exercise of cyber power complements conventional state instruments in pursuit of strategic interests (Gartzke 2013). Yet despite these expectations, interactions involving Southeast Asian states in cyberspace remain pacific.

Neither the Dyadic Cyber Incident and Dispute Dataset (DICD) (Valeriano and Maness 2014) nor the Council for Foreign Relations Cyber Operations Tracker (CFR 2018) shows pronounced levels of regional disruptive or degradative cyber operations. Similarly, the International Institute for Strategic Studies report notes limited interest in offensive cyber strategies ${ }^{1}$ among Southeast Asian states (IISS 2021). This, however, contrasts with the emergence of cyber forces ${ }^{2}$ in Indonesia, Malaysia, the Philippines, Singapore, Thailand, and Vietnam (Blessing 2021). Considering perceptions of increasing cyber conflict juxtaposed against its limited occurrence, the establishment of

${ }^{1}$ For this article, offensive strategies reflect the use of cyber capabilities to disrupt or degrade adversarial capabilities and assets in cyberspace.

${ }^{2}$ Active-duty military organizations with the capability and authority to direct and control strategic cyberspace operations to influence strategic, diplomatic, and/or military interactions (Blessing 2021). 
cyber forces appears paradoxical given the associated costs (Slayton 2017; Borghard and Lonergan 2017).

The rationale believed to underpin state behavior in cyberspace is linked with increasing societal dependence encouraging exploitation in pursuit of strategic gains (Arquilla and Ronfeldt 1993; Hansen and Nissenbaum 2009; Saltzman 2013). And while empirical evidence tempers revolutionary aspirations, states continue to employ cyber operations as an adjunctive signaling instrument (Jensen and Valeriano 2019; Gartzke and Lindsay 2015; Kostyuk 2021). However, our understanding of strategic preferences concerning cyberspace is informed by the behavior of established cyber powers ${ }^{3}$ (Dossi 2020; Kostyuk 2021). The behavior of these actors shape ideas surrounding the exercise of power in and through cyberspace. Furthermore, as these relationships are normalized (Fischerkeller and Harknett 2018b), it becomes necessary to confirm whether a broader range of states share these views (Healey 2019). It is then pertinent to question whether these theories adequately account for the strategic preferences of novice state actors in cyberspace.

Consequently, the article utilizes the Philippines as a case study for the use of cyber operations as a signaling instrument. The strategic environment it faces and its material constraints are expected to result in the utilization of cyber operations as a means of signaling resolve during periods of conflict (Liff 2012) which minimizes escalatory risk (Jensen and Valeriano 2019). To test this claim, the inclusion of cybersecurity as a component of national security is analyzed using policy documents, elite interviews, and

\footnotetext{
${ }^{3}$ The United States, Russia, China, Israel, etc.
} 
third-party reporting. The subsequent analysis of the Influence-Deter-Defend (IDD) strategy adopted by the Philippines (DND 2019a; AFP 2019) reveals that rather than basing its strategic preferences exclusively on material and strategic factors, it stems from established worldviews and normative expectations exogenous to cyberspace. Furthermore, the article posits that observed behavior stems from the underlying strategic culture, "widely shared, identity-driven norms, ideas, and beliefs about the legitimate use of force by the state for the provision of security" (Mirow 2016, 34), that influences the formation of strategic preferences. Consequently, the article advances a mechanism in which the strategic environment is viewed through the ideo-normative lens of regional and national strategic culture that frames preferences that are suitable for a given situation. These observations are significant as the novelty of cyberspace is thought to be a source of external shocks that challenge established beliefs and practices (Lantis 2002; Katzenstein 1996; Hyde-Price 2004). Consequently, the formation of strategic preferences vis-à-vis cyberspace is a hard test for strategic culture.

The remainder of the article is divided into five sections. The following section presents existing frameworks that inform the emergence of strategic preferences in cyberspace. Beginning with early revolutionary narratives, the section argues that states increasingly utilize cyber operations as a communicative instrument. However, questions are raised whether our understanding derived from the behavior of established actors applies to novice cyber powers. This leads to the article's core argument wherein preferences are shaped by the interpretation of material and strategic realities through the lens of strategic culture. This is followed by presenting the case and an overview of Southeast Asian and Philippine strategic culture, which then proceeds to the penultimate section, where the adoption of strategic preferences vis-à-vis cyberspace is analyzed using 
the competing frameworks. Finally, the article concludes by summarizing its findings and implications for cybersecurity scholarship.

\section{State Preferences in Cyberspace}

The strategic value of cyberspace is associated with its role as an enabler for sociopolitical, economic, and military processes (Kuehl 2009). However, empirical evidence over the last two decades suggests that benefits accrued through the exercise of cyber power are far more limited. This section provides an overview of arguments for the revolutionary potential of cyber operations and how these alter interstate interactions in favor of weaker powers. Inversely, the countervailing narrative that calls for a conservative view of cyber operations as a communicative tool is presented as a counterpoint.

\section{Vulnerability, Fragility, and Anonymity}

The enduring narrative that favors the use of cyber operations rests on the perceived vulnerability of cyberspace. As noted by Saltzman (2013), the environment enables wideranging cascading effects that contrasts starkly with conventional instruments in terms of both scope and cost. This is not surprising given how cyberspace is constructed. Libicki (2009b) proposes that cyberspace consists of interdependent layers such that disruptions to one or more trigger cascading effects. As the complexity of cyberspace grows, the likelihood of disruptions, intentional or otherwise, increases given our inability to accurately predict where and how failures occur (Perrow 1984).

Finally, the logical association between the source of an incident and the human operator(s) introduces attributional challenges. This is emphasized by Lin (2016), who notes that while advancements in digital forensic technology permit the identification of 
the point of origin, associating individual computer systems with individuals and enabling authorities is challenging. Consequently, the narrative that cyberspace is an unknowable and unpredictable environment where malicious actors inevitably operate (Dunn Cavelty 2013) is unsurprising. The surge in cybersecurity incidents since the mid-2000s, along with media depictions and political framing of the issue, reinforce the belief in its revolutionary potential (Valeriano and Maness 2015). Consequently, the establishment of cyber forces appears to be a reaction to these beliefs (Dunn Cavelty 2012; Harknett and Smeets 2020).

\section{Aspiration Versus Reality}

While evidence points to increased inter-state interactions in cyberspace, its strategic benefits appear muted. The DICD (Valeriano and Maness 2014) indicates that less than $10 \%$ of degradative and disruptive operations achieve their strategic objective; prompting scholars (Gartzke 2013; Lindsay 2013; Borghard and Lonergan 2017; Whyte 2016; Smeets 2018) to question the extent that technically complex operations shift the balance of power between states. Consequently, Iasiello (2013) observes that cyber operations are a "dull tool" to shape or influence state behavior.

However, we should not dismiss the utility of cyber operations outright. Healey (2016) observes that the last decade saw developments in capabilities resulting in tactical, if not strategic, success. However, achieving the envisioned effects scope requires significant material, technological, and organization resources available only to a handful of actors (Pytlak and Mitchell 2016; Borghard and Lonergan 2017; Slayton 2017). Moreover, even those with the requisite capabilities may find that desired outcomes are more easily achieved by conventional means. Consequently, the notion of cyber 
operations being a "dull tool" is valid insofar as it is used independently of other instruments of power (Gartzke 2013).

This re-orientation is captured by Rovner (2019), who argues that interactions in cyberspace are less of a military contest in pursuit of dominance but more akin to intelligence contests reflecting open-ended competition among adversaries. Reframing interstate interactions this way expands how states conceptualize cyberspace as a component of national security.

\section{Cyber Operations as a Communicative Tool}

A recurring feature linking disparate cybersecurity incidents is their occurrence within the context of ongoing strategic interactions, with established rivals moving their dispute into cyberspace (Maness and Valeriano 2016; Gartzke and Lindsay 2017; Buchanan 2017). While the early literature posits that this will result in unbridled conflict (Clarke and Knake 2014; Forsyth Jr and Pope 2014), a degree of restraint exists between adversaries, suggesting an attempt to maintain the status quo (Maness and Valeriano 2016). While this suggests efforts to manage the unintended consequences of escalation (Fischerkeller and Harknett 2018b; Maness and Valeriano 2016; Jensen and Valeriano 2019), restraint between major powers weakens this argument as substantial conventional capabilities are thought to minimize the risk of escalation (Liff 2012). Instead, Fischerkeller and Harknett (2018a) propose that the presence of agreed competition explains such behavior.

Agreed competition pertains to the situation wherein tacit understanding exists amongst actors in defining the limits of acceptable behavior in cyberspace. These boundaries emerge through repeated interaction that gives rise to observable patterns of 
behavior (Fischerkeller and Harknett 2018a). Agreed competition, in effect, conforms with the concept of an intelligence contest wherein actors compete with, rather than dominate, each other. In response, contemporary cybersecurity scholarship proposes that preferences expressed through cyber operations serve the purpose of signaling resolve and capabilities through the controlled expression of power (Jensen and Valeriano 2019; Kostyuk 2021; Fischerkeller and Harknett 2018a; Brown and Fazal 2021).

Jensen and Valeriano (2019), for instance, assert that cyber operations function as conflict off-ramps. The authors posit that cyber operations offer the means to communicate resolve without risking vertical escalation. Similarly, Borghard and Lonergan (2021) advance a related argument when unpacking the logic of deterrence-bydenial through cyberspace. They note that rather than focusing exclusively on defensive measures, actively engaging in counter-cyber operations is necessary for deterrence success. Relatedly, Carson (2018) utilizes the logic of covert action and likens cyberspace to a backstage that permits actors to engage with each other out of public sight, reducing audience costs (Libicki 2009a). This is supported by Brown and Fazal (2021), who speculate that ambiguous denials serve the purpose of communicating resolve while managing escalatory risk.

Given these developments, one could argue that states view cyber operations as adjunctive instruments whose communicative potential drives interest in cyberspace. Furthermore, the exercise of cyber power is likely to be moderated; the language associated with its use is tempered to signal restraint.

\section{Constraints on Generalizability}

The use of cyber operations as a communicative instrument corresponds with observed 
state behavior. However, this remains a function of (1) actor capabilities and (2) prior interactions that determine the boundaries of acceptable behavior. While offensive tools are readily accessible, the efficacy of operations remains contingent on the ability to demonstrate or suggest the existence of capabilities (Liff 2012; Brown and Fazal 2021). Although operations may be conducted using repurposed tools from the information security community or through exploits obtained via criminal networks, without the corresponding expertise and resources, these are likely to limit their communicative potential (Liff 2012).

In challenging the offensive advantage afforded by cyber operations, Slayton (2017) not only surfaces the necessary technical capabilities but also acknowledges the challenges of acquiring intelligence surrounding defensive capabilities (Gartzke and Lindsay 2015). This is echoed by Borghard and Lonergan (2017) in their investigation of the logic of coercion, noting requisite capabilities for sustained operations that produce coercive effects. Furthermore, the fact that capabilities are nullified once exposed (Axelrod and Iliev 2014) suggests that advanced cyber operations remain the domain of materially endowed actors who can absorb these costs.

Material considerations aside, the strategic context that frames interactions requires further consideration. Fischerkeller and Harknett (2018a) note that stability is a function of implicit rules that surface from repeated interactions, raising doubt whether novice actors recognize these norms of behavior. Healey (2019) argues that novice actors in cyberspace are unlikely to be aware of these, increasing the risk of instability. Experimentally, Gomez (2019a, 2019b) demonstrates that decision-makers base their strategic preferences on established behavior. Furthermore, it appears that in-domain 
exchanges are contextualized by existing rivalry relationships (Maness and Valeriano 2016). If these assumptions are necessary for stability, actors experienced with cyber operations are best suited to reflect this dynamic.

However, only $12(19.7 \%)$ states with existing cyber forces utilize cyber operations (Valeriano and Maness 2014; Blessing 2021). While this statistic only refers to rivalry interactions, this is not problematic as both rivalries and sustained in-domain interactions appear to be necessary conditions for stable relationships to emerge. Consequently, the argument that novice actors utilize cyberspace to manage escalation is further weakened if the conditions for stability are absent.

\section{A National Preference for Cyber Operations}

Frameworks that explain behavior-shaping preferences in cyberspace are influenced by paradigms rooted in latent technological realities and assumptions surrounding cyberspace (Saltzman 2013; Forsyth Jr and Pope 2014). While developments highlight the use of cyber operations for signaling among established powers, limitations surface when applied to novice actors as the communicative potential of cyber operations is contingent on capabilities and established norms of behavior. In response, cybersecurity scholars either allude to or explicitly propose the possibility of distinct national ways of "cyber conflict."

Starting with Hare (2010), who argues that threat perception is a function of sociopolitical realities, others propose that preferences established before the advent of cyberspace exert influence on state actors (Valeriano, Jensen, and Maness 2018). These distinct preferences are reflected in real-world behavior (Kaminska 2021), existing policy documents (Kari and Pynnöniemi 2019), and observations derived from cross-national 
simulations (Gomez and Whyte 2020). However, little effort is expended to develop a framework that considers these priors when analyzing state behavior in cyberspace (Gomez 2021). Consequently, this article posits that distinct national approaches to cyber operations reflect an underlying strategic culture that frames the range of preferences perceived as appropriate.

\section{Defining Strategic Culture}

While strategic culture offers a ready means by which preferences towards cyberspace are analyzed, it remains a contested concept. Early proponents (Snyder 1977; Gray 1981) are often accused of espousing over- and under-determined culture-derived theories of state behavior ${ }^{4}$. Later, scholars adopted a Gramscian approach by distinguishing discourse grounded in strategic culture and operational doctrine (Johnston 1995). Proponents argue that strategic culture enables elites to maintain hegemony while facilitating the advancement of specific doctrines whose consistency with cultural components is not guaranteed. This, however, did not establish the extent to which discourse influences observable behavior (Klein 1988; Kier 2017).

Contemporary strategic culture scholarship features increased rigor concerning theory and method (Legro 1995); however, issues persist. Specifically, debate continues surrounding (1) its relationship with observed behavior (2) and its operational level.

\footnotetext{
${ }^{4}$ First generation strategic culture theories are thought to be under-determined as they leave little room for alternate explanations of state culture while they are perceived as over-determined as these were viewed as an amalgamation of a wide range of (potentially competing) variables (Bloomfield 2012; Johnston 1995).
} 
Analysis that utilizes this construct must address these concerns lest it falls victim to the concept's enduring debates. Moving forward, the article treats strategic culture as "widely-shared, identity-driven norms, ideas, and beliefs about the legitimate use offorce by the state for the provision of security."

\section{Contextualizing Reality}

Strategic culture adopts many definitions that address both its character and level of analysis, resulting in the narrowing and broadening of the concept over time. Snyder $(1977,8)$ treats it as "the sum total of ideas, conditioned emotional responses and patterns of habitual behavior that members of a national strategic community have achieved through instruction and imitation with each other with regard to nuclear strategy." This locates strategic culture among security and political elites that apply it exclusively to questions of nuclear security.

In contrast, later scholars such as Johnston $(1998,36)$ adopt a broader definition such as "an integrated system of symbols which acts to establish pervasive and longlasting preferences by formulating concepts of the role and efficacy of military force in interstate political affairs." This includes issues other than nuclear security while simultaneously abandoning explicit references to a particular sub-unit of decisionmakers. This broadening, however, is not a distinct feature of what has come to be known as the "third-generation" of strategic culture scholarship.

When studying the evolution of French military doctrine during the interwar period, Kier (2017) notes the presence of a distinct organizational culture within the military, which consists of "the set of basic assumptions, values, norms, beliefs, and formal knowledge that shape collective understandings." This suggests the presence of 
sub-, and possibly, supra-cultures as a source of competing preferences. However, these definitions overlap in their notion of strategic culture, providing an ideational lens that gives meaning to material and structural factors (Glenn 2009). Consequently, the ideational construction of strategic culture intersects with the concept of beliefs.

Jervis (2009) argues that beliefs arise out of the need to understand the environment and corresponds with Johnston $(1995,46)$, who views this as the "ideational milieu which limits behavioral choices." This frames the interpretation of the material world by influencing or setting expectations and establishing the plausibility of certain propositions. Relatedly, strategic culture scholars such as Krause and Latham (1997, 24) note that such constructs "help shape an understanding of what constitutes 'normal', 'appropriate', or 'desirable' practices and responses." Consequently, culturally derived preferences follow a logic of appropriateness.

Depicting strategic culture as a lens through which the environment is interpreted is advanced by Mirow (2016) in his analysis of the use of force following the September 11 attacks. He argues that strategic culture represents a formal conditioning cause that gives meaning to events. This treatment coincides with Bloomfield $(2012,445)$, who argues that "ideas and values guide the interpretation of material variables that affect strategic decision-making [. . .] Ideas may therefore act more like intervening variables which provide meaning to material independent variables." Relatedly, others point to the normative expectations of strategic culture - delineating what is appropriate for a given situation. 
It is worth noting that this treatment of strategic culture does not diminish the relevance of material and strategic factors. Instead, these attributes are interpreted using the underlying strategic culture (Gomez 2021; Larson 1994). Furthermore, the degree to which preferences derived from strategic culture fit the environment with respect to normative expectations of rational choice rests on the extent to which the latter mirrors reality (Gigerenzer 2008). Consequently, decision-makers find themselves in a position wherein this ideational lens results in the systematic "slippage between policy-guiding mental representations of reality and reality itself" (Goldgeier and Tetlock 2001, 79).

\section{Strategic Culture and Level of Analysis}

While strategic culture offers a means to interpret the strategic environment, the level at which it becomes relevant remains unanswered. Contemporary scholarship points to multiple competing sub-cultures (Bloomfield 2012; Libel 2016), leading to the question of whose culture is relevant. This becomes even more salient when considering the multitude of actors involved in policymaking. Yet this may not be as problematic if one treats strategic culture as a set of beliefs.

Beliefs are hierarchical, with core beliefs connected to peripheral ones (Larson 1994; George 1969). Kitchen (2010) offers a three-level typology to explain the relationship between strategic ideas and foreign policy choices. At the top are scientific ideas that establish the relationship between components in the international system. Following this are intentional ideas, normative suggestions that represent foreign policy goals. Finally, operational ideas are how scientific and intentional ideas are achieved. Using this typology, one could argue that shared scientific and intentional ideas exist among individuals with a common history or experience they are socialized into, while 
operational ideas may vary as a function of organizational prerogatives (Posen 1986; Harris 1994; Ben-Ephraim 2020).

Linking this with earlier scholarship that posits the role of history in forming strategic culture (Johnston 1995), it is unproblematic to argue that similarities exist across decision-makers. Consequently, one could reasonably conceive the existence of a dominant strategic culture from which sub-cultures emerge due to the competition (Libel 2016). This allows the article to utilize the concept as an analytical tool without necessarily challenging research focused on competition between epistemic communities with distinct sub-cultures. Krause (1997) echoes this when noting the inappropriateness of distinguishing between different levels of culture as "all share overlapping elements." Furthermore, while acknowledging the possibility of sub-cultures, both Kier (2017) and Legro (1994) stress the importance of analyzing culture as a collective phenomenon that cannot be reduced to individuals or organizations.

This, however, does not dismiss the importance of studying variations that emerge from the competition. Instead, recognizing the existence of shared elements may account for the perceived appropriateness of specific policies despite competing preferences. Mirow (2016) notes that shared culture explains the resonance of policies among actors in a single state. For example, while preventing escalation is widely accepted, solutions may vary between those from a diplomatic or military background.

\section{Capturing Strategic Culture}

In defining strategic culture as "widely-shared, identity-driven norms, ideas, and beliefs about the legitimate use of force by the state for the provision of security," its operationalization as an analytical tool needs to be addressed. The definition emphasizes 
the importance of norms for the use of force. Norms refer to beliefs as to what is thought to "work" for security and defense policy. Katzenstein (1996) treats norms as social facts that establish expectations of behavior as an expression of an actor's identity and classifies these as either constituent or regulative norms. Constituent norms are identityderived expectations of how an actor is expected to behave. This is collective and is thought to be thoroughly embedded and corresponds with intentional ideas introduced previously. Complementing this, regulative norms pertain to what works best in achieving goals in the international system and resemble operational ideas.

While other strategic culture scholars propose specific schemes to map these norms onto discernable policy preferences (Mirow 2016; Meyer 2007), utilizing Kitchen's model is appropriate for two reasons. First, its hierarchical structure captures the possibility of supra- and sub-cultures shaping strategic preferences. The plurality of actors responsible for securing and exploiting cyberspace (Burton and Claire 2020; Dunn Cavelty 2013) suggests variations in preferences while contributing towards a shared, overarching, strategic goal. Second, the norms identified by Mirow and Meyer that capture variations in strategic culture, while easily applicable to the conventional environment, prove cumbersome for cyberspace, given the contested nature of territoriality, violence, and coercion.

Consequently, the goal of the subsequent analysis is not to provide a direct link between individual strategic choices made in the domains of land, air, sea, and space with those of cyberspace. Instead, it endeavors to demonstrate that the intent behind these is comparable despite the unique features of cyberspace. Furthermore, it emphasizes that 
preferences are derived from the ideational nature of strategic culture that gives meaning to material and strategic realities.

\section{Case Selection and Context}

As posited, strategic preferences are explained by the underlying strategic culture that frames the interpretation of the material and strategic environment. However, applying this framework to the adoption of preferences in cyberspace is a hard test of the theory due to perceptions of the novelty of the environment and the argument that external shocks encourage a reassessment of established beliefs. Moreover, the exercise of power among novice actors through cyberspace appears better aligned with technological and strategic considerations of the environment. It is for these reasons that the Philippines is selected as an appropriate case.

The Philippines is involved in a salient territorial dispute with China over portions of the South China Sea. This rivalrous relationship sees military and non-military assets utilized in the conventional domain to express territorial claims. These interactions extend into cyberspace with recurring disruptive exchanges between the Philippines and China (CFR 2018; Valeriano and Maness 2014). However, irrespective of issue saliency, exchanges have yet to escalate beyond disruption, corresponding with the expectation of adversarial restraint within tacitly established boundaries (Maness and Valeriano 2016).

The actions of Philippine-based hackers appear less of an attempt to dominate but reflect the need to signal resolve. While there is merit in the argument that the Philippines lacks the requisite capabilities to inflict more significant damage, the state of Chinese cyber infrastructure makes it vulnerable to low impact but visibly disruptive operations (Lindsay 2014; IISS 2021). Moreover, limited state capabilities in cyberspace could be 
augmented by non-state actors whose interests align with those of the Philippine government (Maurer 2018). While proof of such a relationship is unlikely to surface, the absence of attempts by successive administrations to effectively penalize unilateral actions suggests the strategic benefit of allowing these to continue.

However, associating Philippine strategic preferences with its underlying strategic culture is a challenging test due to the environment's presumed novelty. This is reflected in official documents that reflect perceptions towards cyberspace. Similarly, interviews with relevant government agencies such as the Department of National Defense (DND), the Department of Foreign Affairs (DFA), and the Department of Information and Communication Technology (DICT) highlight the disruptive potential of this technology. Tangentially, inexperience with this environment compared to regional neighbors encourages dependence on capable partners when learning how best to utilize the environment (Wallace 2008; Atkinson 2006; Sechser and Saunders 2010; Frazier and Hutto 2017). This reduces the likelihood of employing domestic and regional strategic cultures as the lens through which the material and strategic environment are interpreted. Consequently, demonstrating the ability of strategic culture to explain preferences adopted by the Philippines in these conditions increases our confidence in its explanatory power (George and Bennett 2005).

The case study utilizes policy documents and interviews involving relevant government agencies to test the influence of strategic culture on the formation of preferences towards cyberspace concerning national security. In terms of the former, the National Security Policy (NSP), the National Defense Strategy (NDS), the National Cybersecurity Plan (NCP), and the National Military Strategy (NMS) are analyzed to 
surface how the Philippine government approaches cybersecurity as a component of national security. As for the latter, structured and semi-structured interviews with respondents from the Department of National Defense (DND), Department of Foreign Affairs (DFA), and the Department of Information and Communication Technology (DICT) are conducted to obtain more nuanced views of the preferences communicated by the official documents. These artifacts are analyzed thematically to identify ideas and concepts aligned with the regional and domestic strategic culture. Should these reflect notions that correspond with culturally-derived preferences despite material and strategic realities, then the explanatory power of the framework gains greater legitimacy.

\section{Southeast Asian Strategic Culture}

Southeast Asia's unique historical and geographic features shape strategic preferences in its archipelagic and mainland territories (Wah 2000). While rapid technological and strategic shifts challenge the ability of strategic culture to explain preferences following the end of the cold war (Ball 1993), regional events lend credence to the concept. For instance, Kivimäki (2001) argues that the long peace experienced goes against theoretical expectations given material and strategic factors but corresponds with the underlying cultural expectations. Acharya (1998) identifies the presence of two distinct cultures; a traditional culture emerging from the cultural modes of perception and interaction and synthetic culture that materializes from interaction and socialization that produces longterm habits and attitudes towards managing peace and conflict ${ }^{5}$ (Khong 2004). The latter, relevant to this analysis, emerges from geographic constraints and a history of colonialism that frames and influences regional and external relationships (Wah 2000; Haacke 2003).

\footnotetext{
${ }^{5}$ This is commonly referred to as the ASEAN Way.
} 
The region concerns itself with preventing and managing intra-regional conflict (Acharya 1998; Wah 2000). The absence of strategic depth and the distributed nature of territory stokes fears of intervention by outside powers. Similarly, a history of aggression from external actors encourages a mindset wherein the region is subject to the machinations of great powers (Acharya 2008; Wah 2000). This is exacerbated by competing interests and ideological differences (Baba 2016; Kivimäki 2001) that risk inter- and intra-state conflict. Consequently, diversity management becomes crucial for regional security and is expressed through preferences such as (1) consensus-building, (2) non-confrontational bargaining styles, and (3) pragmatism.

Consensus building is traced to Javanese decision-making practices wherein those with divergent views are not treated as adversaries but as "friends and brothers" (Acharya 1998, 62). Consensus, in this context, does not speak to unanimity but instead points to a common subjective perception of shared interests (Kivimäki 2001). Consequently, regional interactions exhibit a preference for solutions that reflect a shared understanding of the problem without necessitating complete agreement (Acharya 1998; Baba 2016). Complementing consensus building, regional relations are characterized by a non-confrontational bargaining style reflected by non-publicized disputes and discrete negotiations. This also tends to avoid identifying individual actors as threats that risk security-seeking behavior. Finally, Ball (1993) notes that pragmatism is a common feature in Asian and Southeast Asian culture. The transition from colonies to independent states beginning in the late 1940s and the eventual establishment of ASEAN saw the abandonment of idealism in pursuit of strategic objectives. 
Consequently, Southeast Asian strategic culture strives towards stability and the avoidance of overt interstate competition. To achieve this, states adopt consensus building, non-confrontational strategies, and pragmatism to pursue regional stability.

\section{Philippine Strategic Culture}

While Philippine strategic culture shares similarities with that of its regional counterpart, distinct features exist. Its conceptualization of national security, including territorial defense and the people's interests (Villacorta 1999), corresponds with comprehensive security (Acharya 1998) practiced in the region. This differs from western conceptions with its emphasis on internal stability and security. Furthermore, the military's role is expanded beyond defense and includes other socio-political and economic aspects. However, the primacy placed by other regional actors on the military is diminished in the case of the Philippines (Villacorta 1999).

The reduced prominence of the military is tied to geographic features and experience with confronting more capable actors. Limited resources and geographic fragmentation made the development of a large centralized pre-colonial polity that supported a complex military organization difficult. Consequently, these same constraints decreased the likelihood of a coordinated defense against external threats (Villacorta 1999). Relatedly, its involvement in interstate conflict is historically not of its own making and is the consequence of great power rivalry (Wah 2000). This is not to say that it is not conflict-prone. Enduring socio-economic concerns and identity issues are at the core of persistent internal security concerns (De Castro 2014). Finally, recent experience with martial law does little to improve the esteem shown to the defense sector. 
Complicating matters, the country's maritime borders are thought to provide it with a defense against external threats (De Castro 2014), leading political elites to show little interest in strategic matters. This is problematic, as the defense sector is beholden to these elites and struggles to gain support without compromising elite interests (Haacke 2003; De Castro 2014). This confluence of factors leads to a strategic culture that shuns militarization in favor of conflict avoidance (Villacorta 1999). Moreover, pursuing these objectives results in a dependence on alliances to prevent the outbreak of conflict. However, should conflict occur, asymmetric strategies are pursued owing to limited material capabilities.

A preference for conflict avoidance sees the Philippines leveraging existing alliances to provide it with security guarantees. Most notably, the continued presence of the US military following the Second World War and bilateral security agreements provided a deterrent against external threats. This sense of security allowed elites to deprioritize external defense and, instead, focus on internal security issues perceived as a threat to their interests (De Castro 2014). Following the collapse of negotiations and the abandonment of US military facilities, modernization efforts were undertaken to improve defensive capabilities. Alongside these initiatives, priority is still given to maintaining and enhancing existing ties with allied and partner states to provide security guarantees (Haacke 2003).

Should conflict occur, material constraints force decision-makers to pursue security by any means possible. Historically, conflict demonstrated a penchant for utilizing its geographic features to gain an asymmetric advantage over materially endowed adversaries. However, even when attempts to improve material capabilities are 
undertaken, defense planners invoke asymmetric defense strategies that proved helpful in the past (De Castro 2014).

As with the regional strategic culture, the Philippines prioritizes stability and conflict avoidance. In addition, it continues to foster exiting alliances and partnerships to provide it with security guarantees in support of these objectives. Should this fail, however, limited material capabilities force the adoption of asymmetric strategies.

\section{Case Analysis}

The earliest mention of cybersecurity as a component of national security is in the 2011 - 2016 National Security Policy (NSP) in the context of law enforcement (NSC 2011). This broadens in the subsequent version with its inclusion in the twelve-point national security agenda (NSC 2017). Specifically, it becomes the objective of the government to "safeguard our classified action plans and programs, sensitive government intentions, and state secrets from espionage and other hostile actions to protect and preserve national security interests. In addition, shield the country from computer-generated / cyber attacks that could cause massive crises in our economy, banking and financial institutions, communications, and other critical infrastructures" (NSC 2017, 25). This phrasing is crucial given its reference to the preservation of national security interests.

Defined as "a state or condition wherein the people's welfare, well-being, ways of life; government and its institutions; territorial integrity; sovereignty; and core values are enhanced and protected" (NSC 2017, 2), the concept of national security highlights both material and immaterial factors in keeping with the idea of comprehensive security. This is crucial as the NSP is the foundation on which other policy documents such as the National Defense Strategy (NDS) and the National Military Strategy (NMS) are based. 
While the study of strategic preference towards cyberspace should include all relevant agencies, analysis is limited to the defense sector as the projection of power externally through cyberspace is assigned to these organizations as per the National Cyber Security Plan (NSP) (DICT 2019).

The Philippines treats cyberspace as the fifth domain of warfare along with air, land, sea, and space (DND 2018). Its strategic value is reflected in its inclusion as a defense mission $\operatorname{area}^{6}$ in the first National Defense Strategy published by the DND. These mission areas support five strategic objectives of Philippine national security, (1) sovereignty and territorial integrity of the state secured, (2) internal stability promoted and sustained, (3) highest standard or capability and preparedness on disasters attained, (4) operations in support of global peace and security improved and sustained, and (5) good governance upheld (DND 2018, 36). In this regard, cybersecurity is identified as an external defense mission area that covers "the maritime area over which the Philippines has sovereignty and/or enjoys sovereign rights, as well as space and cyber domains" (DND 2018, 45). This is associated with the first two strategic objectives that are fundamental to Philippine national security.

This mission area is achieved through the Influence-Deter-Defend (IDD) strategy developed in response to the growing complexity and uncertainty of the strategic environment (DND 2019a; AFP 2019). Influence refers to shaping the operational

\footnotetext{
${ }^{6}$ Defense mission areas provide the foundation for defining missions and tasks assigned to the respective bureaus of the department which includes the Armed Forces of the Philippines (AFP).
} 
environment through a whole-of-nation approach in conjunction with continued engagement with allies and partners. Moving on, deterrence refers to the continued development of capabilities to achieve a defensive posture that discourages aggression. Deterrence in this context includes the ability to draw support from the international allies and partners to provide security guarantees. Defend, finally, is invoked following deterrence failure and asserts the need to win against external and internal threats using all available resources and capabilities.

\section{Reaction to Strategic and Technological Realities}

Recurring cybersecurity incidents, often in the context of latent territorial disputes with China (Valeriano and Maness 2014; CFR 2018), find the inclusion of cybersecurity as a component of national security unsurprising. Following disruptive operations in April 2012 (Segal 2012), the Department of Defense (DND) released a whitepaper recognizing cyberspace as a strategic national asset (DND 2012). However, recognition of its strategic significance pre-dates this document.

Respondents from the DND note that cybersecurity was seen as an issue as early as 2009. Moreover, cybersecurity was perceived as a "priority security concern" due to the digitalization of defense systems and institutions to which it is obligated to defend. This timing is relevant as the Philippines did not experience sustained cyber operations before 2012, suggesting that perceptions of vulnerability are less a function of first-hand experience. Moreover, incidents after 2012 showed no sign of inflicting significant damage to Philippine strategic interests. Consequently, it seems unlikely that perceptions of the strategic importance of cyberspace coalesced around these incidents. Instead, the decision to elevate cybersecurity as a national security issue follows the argument 
advanced by Dunn-Cavelty (2012) that prominent cybersecurity incidents prompt the development of policies and capabilities globally. This view is confirmed by respondents from the DND and the DICT, who cite external incidents as stimulating interest in the issue. Thusly, the inclusion of cybersecurity as a component of national security does not appear to be a reaction to a radical shift in the security environment. This, instead, seems anticipatory, echoing the fears and expectations of other actors.

While material constraints temper the adoption of particular strategies, the significance of cybersecurity in defense policy and the establishment of the Armed Forces of the Philippines Cyber Group (AFP-CYG) in 2017 suggests the desire to operate in this space (AFP 2017). As noted by former AFP Chief of Staff Gen. Eduardo Año (AFP 2017), "a secure and resilient AFP cyberspace is a key component in attaining complete information superiority." As Kostyuk (2021) asserts, public cyberinstitutions ${ }^{7}$ such as the AFP-CYG are established to signal resolve without immediate possession of capabilities comparable to established cyber powers. Unfortunately, further analysis raises doubt whether the Philippines intends to utilize cyberspace as a communicative instrument. This suspicion revolves around (1) the authorities granted to the DND and the AFP-CYG, (2) organizational constraints of the AFP-CYG, and (3) the response to Philippine-based nonstate actors in cyberspace.

\footnotetext{
${ }^{7}$ Defined as "publicly observable proactive efforts aimed at signaling its offensive and defensive cybercapabilities" (Kostyuk 2021, 2)
} 
While cybersecurity seems a priority for the defense sector, the National Cybersecurity Plan constraints their scope of responsibility. The document tasks the defense sector to defend national security and military systems and provide intelligence regarding potential foreign threats. For incidents outside its jurisdiction, however, the defense sector is expected to play a supporting role. Relatedly, both the DND and the AFP-CYG appear to lack the authorities required to address incidents independent of other departments. Respondents confirm that the DICT is responsible for determining the level of involvement of the DND and the AFP-CYG following an incident, constraining independent action by the defense sector.

Besides existing authorities, the ability of the AFP-CYG to communicate resolve is further constrained by its structure. The AFP-CYG is under the authority of the Communications, Electronic, and Information Services (J6) within the General Headquarters of the Armed Forces of the Philippines, where it supports existing AFP missions (AFP 2017). Consequently, this characterizes Philippine cyber forces as having a branch organizational model and a subordinated scale of command ${ }^{8}$. While the AFPCYG is the primary Philippine cyber force, other units exist across the different services and are engaged in their own capacity-building programs (Mangosing 2021; Nepomuceno 2020).

\footnotetext{
${ }^{8}$ Blessing (2021) proposes that cyber forces could be classified based on their organizational model (branch, service, or joint) and the scale of command (subordinated, sub-unified, unified).
} 
Similarly, attempts to acquire a greater scale of command are inhibited by fiscal and organizational expectations. A respondent from the DND noted that while the AFPCYG does not aspire to become an independent command, it seems interested in detaching itself from J6, becoming a sub-unified force where cyber operations exist as independent missions. The costs incurred by establishing organizations such as the AFPCYG serve to communicate resolve. However, as Blessing (2021) argues, ceteris paribus, unified cyber forces with a greater command scale, are likely to be better resourced. Consequently, the organizational constraints imposed on the AFP-CYG does not constitute a particularly costly signal.

Finally, the response of the Philippine government towards non-state actors whose actions seem aligned with its interests is telling of the communicative use of cyber operations. Following the exchange between China- and Philippine-based hackers, Philippine authorities called on its citizens "to exercise civil temperance at a time when emotions are running high," suggesting that these actions are counterproductive (Pedrasa 2012). Similarly, a respondent noted that actions by Philippine-based hackers prompted security concerns within the defense establishment. These points are significant as disavowing non-state actors runs counter to the opportunity to utilize this resource to engage in low-level disruptive operations (Maurer 2018). The limited nature of their actions is unlikely to provoke a significant response and could serve to communicate the salience of a particular issue. Similarly, identifying these actors as a potential threat indicates the unwillingness of the Philippines to augment its ability to communicate resolve with the help of non-state actors.

\section{Reflections of Strategic Culture}

The issues that surfaced previously challenge the communicative value of emergent 
public cyberinstitutions in the Philippines. This contests the expectation in interviews with the DND and other relevant departments, which suggest that global trends shape Philippine strategic preferences. However, these could instead reflect domestic and regional preferences emphasizing stability and conflict avoidance through nonconfrontation and alliances.

Applying the Philippines' IDD strategy to cyberspace indicates a deterrence-bydenial approach towards security. Borghard and Lonergan (2021) argue that success not only requires passive defense but disruption of adversarial capabilities. Although the absence of explicit mention of offensive operations is unsurprising, there is limited evidence to support interest in such. First, none of the policy documents identify an adversary the Philippines wishes to deter against. Interestingly, China is recognized as an emergent security partner rather than a threat (DND 2018, 24). This is surprising as it is often featured in threat narratives (Perez-Rubio 2021; Venzon 2019). Second, the authorities of the defense sector and the structure of the AFP-CYG communicate limited resolve. By constraining its actions and resources, interest in projecting force beyond Philippine cyberspace seems minimal. Finally, the repudiation of domestic non-state actors suggests the monopolization of force in this environment and its constraints.

Collectively, these actions reflect the reluctance of the Philippines to engage in offensive cyber operations by adopting an exclusively defensive posture. Setting aside questions of strategic efficacy, this non-confrontational approach suggests an attempt to maintain stability by avoiding escalation despite the vulnerability of certain adversaries such as China. Scholars such as Lindsay (2014) argue that Chinese emphasis on content control leaves it exposed and vulnerable. Consequently, operations that aspire to achieve 
low-level disruption for signaling and reducing audience cost during periods of heightened interstate conflict are plausible (Jensen and Valeriano 2019). However, selfimposed constraints reflected by its defensive posture and unwillingness to identify adversaries by name suggests a non-confrontational strategy aimed at minimizing conflict - in keeping with domestic and regional preferences.

Outside the domestic sphere, Philippine policy at a regional level exhibits a preference for non-confrontation. While the ADMMP-CEWG recognizes the threat posed by cybersecurity incidents, none of the statements issued during its chairmanship explicitly identifies threat actors. Participants in this forum who were among the respondents note that emphasis was placed on finding common ground that enables defense cooperation, including capacity and confidence-building measures (Gomez and Tran Dai 2018). This is crucial as malicious cyber operations affecting this group have been attributed to its members (Gomez 2017). Despite this, no attempt is made to address these disputes. Instead, respondents assert that effort was spent on initiatives aimed at bridging capability gaps between members.

As with non-confrontation, reliance on allies and partners corresponds with historical domestic preferences. Although the relationship between alliances and cybersecurity surfaced as early as 2007 with the DDoS attack on Estonia raising the possibility of invoking Article 5, our understanding of the impact of alliances on cyber conflict remains limited at best (Smeets 2020). While one might argue that developments within NATO raise the cost of malicious behavior against members (NATO 2019), this was announced after the publication of the current Philippine policy and is unlikely to have influenced its development. However, despite the absence of formalized 
declarations (Manantan 2021), the importance of existing relationships in the IDD strategy is reflected in initiatives between the Philippines and its sole treaty ally, the United States. These include cybersecurity exercises during the annual Balikatan Exercises (Nepomuceno 2021) and the establishment of the US-Philippines Joint Cybersecurity Working Group (Manantan 2021). Consequently, it is unsurprising that the language of capacity building continues to be employed when talking about joint exercises (e.g., ASEAN) (Gomez and Tran Dai 2018). More importantly, these focus primarily on defense rather than projecting offensive capability, as confirmed by press releases (Pettis 2017; DND 2019b) and respondents. Moreover, public declarations of the defensive nature of such exercises further reflect this preference for non-confrontation, allaying fears of attempts to develop offensive capabilities. Consequently, these actions improve passive defensive capabilities while minimizing the risk of confrontation and misperceptions, further strengthening the argument for culturally derived strategic preferences.

\section{Alternative Accounts}

Despite alignment with domestic and regional strategic culture, alternative explanations may account for the strategy adopted by the Philippines. The article advances two alternative arguments based on (1) limited material resources and (2) a lack of domain expertise.

Arguing that the lack of resources limits the development and practice of offensive cyber operations is a viable argument given the challenges faced by the Philippines in modernizing its armed forces. Respondents from the DICT and the DND acknowledge that resource constraints are the primary stumbling block in improving Philippine cyber capabilities. However, this alone does not explain the strategic posture adopted. As noted 
by Kostyuk (2021), signaling resolve is not solely achieved through offensive operations. Allowing the defense sector to engage more freely in cyberspace regarding its scope of responsibilities and mission signals resolve. Moreover, Harknett and Smeets (2020) argue that we must abandon the notion of highly degradative and costly cyber operations as determining strategically relevant action. Even minor disruptive capabilities, when used appropriately, can serve a strategic, communicative purpose (Brown and Fazal 2021). Tangentially, the dual-use nature of cyberspace allows for progress in defensive capabilities to inform offensive ones. As argued by Gartzke and Lindsay (2015), defensive technologies may be adapted to deceive adversaries that, in turn, may be used to communicate resolve once they are lured into a fall sense of security.

The need to invest in resources to improve cybersecurity in the Philippines is not lost on political elites. Recent developments, such as the arrival of a third telecommunications provider with ties to China, called for the renewed defense of Philippine cyberspace (Venzon 2019). However, respondents note the sectoral view held by the government concerning cybersecurity. As per the NCP, multiple departments are assigned different responsibilities, with the DICT functioning as the coordinator. While promoting decentralization, this could result in the emergence of underlying biases. Villacorta (1999), spending on the defense sector is often met with increased public suspicion. Add to this its dependency on political elites, the likelihood that available resources are knowingly diverted as a matter of political expediency increases. Consequently, while resources are indeed in high demand, underlying preferences rooted in strategic culture may ultimately explain the lack of support for the defense sector. 
Apart from resources, the lack of domain expertise may similarly account for the strategic posture adopted by the Philippines. Hansen and Nissenbaum (2009) argue that the absence of experts among elites facilitates the emergence of inappropriate policy choices. Moreover, experimental and pseudo-experimental research (Shandler, Gross, and Canetti 2021; Schneider 2017) identify this as contributing to both support for retaliatory action and fear of escalation. For this analysis, the inability to measure domain expertise makes it challenging to assess the extent of its influence on policy. However, if we assume that policy decisions emerge from a lack of expertise, then the strategy adopted may be due to fears of escalation.

Cyberspace as an enabler for socio-economic development is a motivating factor that drives cybersecurity policy. Consequently, concern that offensive operations from the Philippines would provoke retaliation on its infrastructure is unsurprising. However, it should be noted that cyber conflict involving the Philippines and its adversaries is limited. While disruptions frequently occur, these are often limited to denial-of-service or defacement that inflict minimal and transient damage. Even during periods of heightened tension, these operations and their targets remain consistent and have not spilled over into the conventional space. If the decision of the Philippines to adopt an exclusively defensive posture stems from fears of escalation, the case of Vietnam proves an interesting counterpoint to this argument. As with the Philippines, the rivalry between Vietnam and China has crossed over into cyberspace (Valeriano and Maness 2014). However, the decision of the former to enhance its cyber capabilities does not appear to have altered the relationship between the two. While this example cannot independently dismiss the possibility of escalation, it suggests that investment in cyber capabilities alone will not change the strategic calculus (Gompert and Libicki 2014). 
The lack of expertise may aggravate uncertainty concerning adversarial reaction following attempts by the Philippines to improve its cyber capabilities. Under these circumstances, elites may opt to revert to established modes of behavior that served them well in the past (Welch 2011). Consequently, preferences derived from domestic and regional strategic culture may offer them a solution out of this conundrum. If indeed the case, then the lack of expertise is not the primary determinant of strategic preferences. Instead, the uncertainty that emerges from the inability to understand the environment requires decision-makers to instrumentalize strategic culture to mediate its effects, shaping policy preferences (Gomez 2021; Kaminska 2021).

\section{Conclusion}

Conceptions of cyberspace as revolutionizing interstate relations continue to erode. With continued theoretical development and an increasing body of empirical evidence, cyber operations are less a means through which dominance is exerted but are, instead, communicative instruments in conjunction with other foreign policy tools. However, its capacity to signal resolve remains subject to resource availability and tacitly agreed to norms of behavior. The former determines the degree to which resolve is successfully communicated, while the latter frames the range of permitted behavior that minimizes escalatory risk. While this perspective finds robust support in the behavior of established cyber powers, the same cannot be surmised for novice actors.

This article argues that the conditions necessary for the communicative use of cyber operations are limited to actors already established in cyberspace. Consequently, an alternative framework is needed to unpack the strategic preferences of novice actors. To achieve this, the article advances the argument that these actors utilize their strategic 
culture to form preferences that shape policy choices in cyberspace. Using the Philippines as a hard test for this framework, existing policy documents and interviews surface the influence of domestic and regional strategic culture on strategy. While presented as deterrence-by-denial, closer inspection reveals it to be purely defensive. Furthermore, the rationale underpinning it emerges from a logic of appropriateness rooted in the normative expectations of domestic and regional strategic culture rather than a cost-benefit assessment informed by the material and strategic environment.

By surfacing the influence of strategic culture, two crucial contributions to cybersecurity scholarship are established. First, highlighting divergent mechanisms at work between established and novice actors in cyberspace calls attention to the extent to which existing frameworks are based on a limited subset of actors. While the exercise of power through cyberspace originated with North American and European actors, an increasing number of states outside these regions are operating in cyberspace. Unfortunately, the community has yet to recognize the importance of this development. Consequently, the continued growth of cybersecurity scholarship is contingent on our willingness to consider these actors and integrate their experience in our analysis.

Second, integrating factors other than technology and the strategic environment allows for the holistic analysis of cybersecurity policy development. While technology and the strategic environment contribute significantly to the decision-making processes, recent scholarship acknowledges the value of other, less tangible factors. For instance, cognitive and affective mechanisms that shape elite and non-elite behavior in cyberspace are seen to complement technologically deterministic frameworks (Shandler, Gross, and Canetti 2021; Gomez and Whyte 2020). Scholars continue to posit possible "national 
ways" of cyber conflict without proffering a robust theoretical framework to support it. It is in this gap that the article finds itself. By demonstrating that preferences are derived from prior modes of action, scholars and policy specialists are given an additional analytical tool to evaluate state behavior. Furthermore, it serves to weaken the problematic belief that the unique attributes of cyberspace render existing theoretical instruments obsolete, requiring the development of concepts specific to this human-made space. 


\section{References}

Acharya, Amitav. 1998. "Culture, security, multilateralism: The "ASEAN way'and regional order." Contemporary Security Policy 19 (1):55-84.

_ 2008. "Rethinking Singapore's Foreign Policy." In Singapore's Foreign Policy: The Search for Regional Order, 1-10. Denver: World Scientific.

AFP. 2021. "AFP to Strengthen 'Cyber Workforce'." Armed Forces of the Philippines, Accessed 15.10. https://www.afp.mil.ph/index.php/news/8-afp-news/436-afp-tostrengthen-cyber-workforce.

- 2019. "National Military Strategy." In, edited by Armed Forces of the Philippines. Quezon City: Armed Forces of the Philippines.

Arquilla, John, and David Ronfeldt. 1993. "Cyberwar is coming!" Comparative Strategy $12(2): 141-65$.

ASEAN. 2017. "ASEAN ICT Masterplan 2020." ASEAN, Accessed 12.05. https://www.trc.gov.kh/wp-content/uploads/2016/10/1.pdf.

Atkinson, Carol. 2006. "Constructivist Implications of Material Power: Military Engagement and the Socialization of States, 1972-2000." International Studies Quarterly 50 (3):509-37.

Axelrod, Robert, and Rumen Iliev. 2014. "Timing of cyber conflict." Proceedings of the National Academy of Sciences 111 (4):1298-303.

Baba, Gürol. 2016. "Regional commonalities and regional identities: forging a normative understanding of Southeast Asian identity." Journal of Current Southeast Asian Affairs 35 (1):91-121.

Ball, Desmond. 1993. "Strategic culture in the Asia-Pacific region." Security Studies 3 (1):44-74.

Ben-Ephraim, Shaiel. 2020. "From strategic narrative to strategic culture: Labor Zionism and the roots of Israeli strategic culture." Comparative Strategy 39 (2):145-61.

Blessing, Jason. 2021. "The Global Spread of Cyber Forces, 2000-2018." In 13th International Conference on Cyber Conflict (CyCon). IEEE.

Bloomfield, Alan. 2012. "Time to Move On: Reconceptualizing the Strategic Culture Debate." Contemporary Security Policy 33 (3):437-61. doi: 10.1080/13523260.2012.727679.

Borghard, Erica D., and Shawn W. Lonergan. 2017. "The Logic of Coercion in Cyberspace." Security Studies 26 (3):452-81. . 2021. "Deterrence by denial in cyberspace." Journal of Strategic Studies:1-36.

Brown, Joseph M., and Tanisha M. Fazal. 2021. "\#SorryNotSorry: Why states neither confirm nor deny responsibility for cyber operations." European Journal of International Security:1-17.

Buchanan, Ben. 2017. The Cybersecurity dilemma: Hacking, trust and fear between nations. London: Hurst \& Company.

Burton, Joe, and Lain< Claire. 2020. "Desecuritising cybersecurity: towards a societal approach." Journal of Cyber Policy 5 (3):449-70.

Carson, Austin. 2018. Secret Wars: Covert Conflict in International Politics. Princeton: Princeton University Press.

$\begin{array}{lllll}\text { CFR. 2018. "Cyber Operations } & \text { Tracker." Accessed }\end{array}$ https://www.cfr.org/interactive/cyber-operations.

Clarke, Richard Alan, and Robert K. Knake. 2014. Cyber war: Tantor Media, Incorporated.

De Castro, Renato Cruz. 2014. "Philippine Strategic Culture: Continuity in the Face of Changing Regional Dynamics." Contemporary Security Policy 35 (2):249-69. 
DICT. 2019. "National Cybersecurity Plan." In, edited by Department of Information and Communications Technology. Quezon City: Department of Information and Communications Technology.

DND. 2012. "Transforming the Department of National Defense to Effectively Meet the Defense and Security Challenges of the 21st Century." In, edited by Department of National Defense. Quezon City: Department of National Defense.

2018. "National Defense Strategy 2018 - 2022." In, edited by Office of the Assistant Secretary for Plans and Programs. Quezon City: Department of National Defense.

. 2019a. "2019 Accomplishment Report." In, edited by Department of National Defense. Qezon City: Department of National Defense.

- 2021. "ADMM-Plus conducts Table-Top Exercise on Cyber Security." Department of National Defenase, Accessed 16.10. https://www.dnd.gov.ph/Postings/Post/ADMM-Plus\%20conducts\%20TableTop $\% 20$ Exercise $\% 20$ on $\% 20$ Cyber $\% 20$ Security $/$.

Dossi, Simone. 2020. "On the asymmetric advantages of cyberwarfare. Western literature and the Chinese journal Guofang Keji." Journal of Strategic Studies 43 (2):281308.

Dunn Cavelty, Myriam. 2012. "The Militarisation of Cyberspace: Why less may be better." In 2012 4th International Conference on Cyber Conflict, edited by Christian Czosseck, Rain Ottis and Katharina Ziolkowski, 1-13. Tallinn: IEEE.

_ 2013. "From Cyber-Bombs to Political Fallout: Threat Representations with an Impact in the Cyber-Security Discourse." International Studies Review 15 (1):105-22.

Fischerkeller, Michael P., and Richard J. Harknett. 2018a. "Persistent Engagement and Tacit Bargaining: A Path Toward Constructing Norms in Cyberspace." In Lawfare.

2018b. "Persistent Engagement, Agreed Competition, Cyberspace Interaction Dynamics and Escalation." Orbis (Summer 2017) 61 (3):381-93.

Fleishman, Glenn. 2000. "Cartoon Captures Spirit of the Internet." In The New York Times. New York: The New York Times.

Forsyth Jr, James Wood, and Maj Billy E Pope. 2014. "Structural Causes and Cyber Effects Why International Order is Inevitable in Cyberspace." Strategic Studies Quarterly 8 (4):112-28.

Frazier, Derrick V., and Wesley Hutto. 2017. "The socialization of military power: security cooperation and doctrine development through multinational military exercises." Defence Studies 17 (4):379-97.

Gartzke, Erik. 2013. "The myth of cyberwar: bringing war in cyberspace back down to earth." International Security 38 (2):41-73.

Gartzke, Erik, and Jon R. Lindsay. 2015. "Weaving Tangled Webs: Offense, Defense, and Deception in Cyberspace." Security Studies 24 (2):316-48. . 2017. "Thermonuclear cyberwar." Journal of Cybersecurity 3 (1):37-48.

George, Alexander L. 1969. "The" operational code": A neglected approach to the study of political leaders and decision-making." International studies quarterly 13 (2):190-222.

George, Alexander L., and Andrew Bennett. 2005. Case studies and theory development in the social sciences, BCSIA studies in international security. Cambridge, Mass.: MIT Press.

Gigerenzer, Gerd. 2008. "Why Heuristics Work." Perspectives on Psychological Science $3(1): 20-9$. 
Glenn, John. 2009. "Realism versus Strategic Culture: Competition and Collaboration?" International Studies Review 11 (3):523-51. doi: 10.1111/j.14682486.2009.00872.x.

Goldgeier, James M., and Philip E. Tetlock. 2001. "Psychology and International Relations Theory." Annual Review of Political Science 4:67 - 92.

Gomez, Miguel Alberto. 2017. "Frustrated with the Philippines, Vietnam Resorts to Cyber Espionage." In Net Politics, edited by CFR. Council on Foreign Relations. . 2019a. "Past behavior and future judgements: seizing and freezing in response to cyber operations." Journal of Cybersecurity 5 (1):tyz012. . 2019b. "Sound the alarm! Updating beliefs and degradative cyber operations." European Journal of International Security 4 (2):190-208. 2021. "Overcoming uncertainty in cyberspace: strategic culture and cognitive schemas." Defence Studies 21 (1):25-46.

Gomez, Miguel Alberto, and Candice Tran Dai. 2018. "Challenges and opportunities for cyber norms in ASEAN." Journal of Cyber Policy 3 (2):217 - 35.

Gomez, Miguel Alberto, and Christopher Whyte. 2020. "Cyber Wargaming: Grappling with Uncertainty in a Complex Domain." Defense Strategy and Assessment Journal 10 (1):98-139.

Gompert, David C., and Martin Libicki. 2014. "Cyber warfare and Sino-American crisis instability." Survival 56 (4):7-22.

Gray, Colin S. 1981. "National style in strategy: The American example." International security $6(2): 21-47$.

Haacke, Jürgen. 2003. ASEAN's Diplomatic and Security Culture: Origins, development and prospects. New York: Routledge.

Hansen, Lene, and Helen Nissenbaum. 2009. "Digital Disaster, Cyber Security, and the Copenhagen School." International Studies Quarterly 53 (4):1155-75.

Hare, Forrest. 2010. "The Cyber Threat to National Security: Why Can't We Agree?" Conference on Cyber Conflict, Proceedings 2010:211-25.

Harknett, Richard J., and Max Smeets. 2020. "Cyber campaigns and strategic outcomes." Journal of Strategic Studies. doi: 10.1080/01402390.2020.1732354.

Harris, Stanley G. 1994. "Organizational culture and individual sensemaking: A schemabased perspective." Organization Science 5 (3):309 - 21.

Healey, Jason. 2016. "Winning and losing in cyberspace." In 2016 8th International Conference on Cyber Conflict, edited by Nikolaos Pissanidis, Henry Rõigas and Matthijs Veenendaal, 37-49. Tallinn: IEEE.

2019. "The implications of persistent (and permanent) engagement in cyberspace." Journal of Cybersecurity 5 (1):tyz008.

Hyde-Price, Adrian. 2004. "European security, strategic culture, and the use of force." European Security 13 (4):323-43.

Iasiello, Emilio. 2013. "Cyber attack: A dull tool to shape foreign policy." In 2013 5th International Conference on Cyber Conflict, edited by Karlis Podins, Jan Stinissen and Markus Maybaum, 451-70. Tallinn: IEEE.

IISS. 2021. "Cyber Capabilities and National Power: A Net Assessment." In. London: The International Institute for Strategic Studies.

Jensen, Benjamin, and Brandon Valeriano. 2019. "What Do We Know About Cyber Escalation? Observations from Simulations and Surveys." In Issue Brief. Scowcroft Center for Strategy and Security.

Jervis, Robert. 2009. "Understanding beliefs and threat inflation." American Foreign Policy and the Politics of Fear: Threat Inflation since 9 (11):16-39. 
Johnston, Alastair I. 1998. Strategic culture and grand strategy in Chinese history. Princeton: Princeton University Press.

Johnston, Alastair Ian. 1995. "Thinking About Strategic Culture." International Security 19 (4):32-64. doi: Doi 10.2307/2539119.

Kaminska, Monica. 2021. "Restraint under conditions of uncertainty: Why the United States tolerates cyberattacks." Journal of Cybersecurity 7 (1).

Kari, Martti J., and Katri Pynnöniemi. 2019. "Theory of strategic culture: An analytical framework for Russian cyber threat perception." Journal of Strategic Studies:1 29.

Katzenstein, Peter J. 1996. Cultural Norms and National Security: Police and Military in Postwar Japan. Ithaca: Cornell University Press.

Khong, Yuen Foong. 2004. "Coping with Strategic Uncertainty: The Role of Institutions and Soft Balancing in Southeast Asia's Post-Cold War Strategy." In Rethinking Security in East Asia: Identity, Power and Efficiency, edited by J.J. Suh, Peter J. Katzenstein and Allen Carlson. Stanford: Stanford University Press.

Kier, Elizabeth. 2017. Imagining war: French and British military doctrine between the wars. Vol. 153: Princeton University Press.

Kitchen, Nicholas. 2010. "Systemic pressures and domestic ideas: a neoclassical realist model of grand strategy formation." Review of International Studies 36 (1):11743. doi: 10.1017/S0260210509990532.

Kivimäki, Timo. 2001. "The long peace of ASEAN." Journal of Peace Research 38 (1):5-25.

Klein, Bradley S. 1988. "Hegemony and strategic culture: American power projection and alliance defence politics." Review of international studies 14 (2):133-48.

Kostyuk, Nadiya. 2021. "Deterrence in the Cyber Realm: Public versus Private Cyber Capacity." International Studies Quarterly.

Krause, Keith. 1997. "Cross Cultural Dimensions of Multilateral Non-Proliferation and Arms Control Dialogues: An Overview." In Cross-cultural Dimensions of Multilateral Non-proliferation and Arms Control Dialogues, edited by Keith Krause, 1-17. Ottawa: Department of Foreign Affairs and International Trade.

Krause, Keith, and Andrew Latham. 1997. "Culture and the Construction of Western Nonproliferation, Arms Control and Disarmament Practice." In Cross-cultural Dimensions of Multi-lateral Non-proliferation and Arms Control Dialogues, edited by Keith Krause, 19-48. Ottawa: Department of Foreign Affairs and International Trade.

Kuehl, Daniel T. 2009. "From Cyberspace to Cyberpower: Defining the Problem." In Cyberpower and National Security, edited by Franklin D.; Starr Kramer, Stuart H.; Wentz, Larry, 24-42. Dulles: Potomac Books.

Lantis, Jeffrey S. 2002. "Strategic Culture and National Security Policy." International Studies Review 4 (3):87-113. doi: 10.1111/1521-9488.t01-1-00266.

Larson, Deborah Welch. 1994. "The role of belief systems and schemas in foreign policy decision-making." Political Psychology:17-33.

Legro, Jeffrey. 1995. Cooperation Under Fire: Anglo-German Restraint During World War II: Cornell University Press.

Legro, Jeffrey W. 1994. "Military Culture and Inadvertent Escalation in World War II." International Security 18 (4):108-42.

Libel, Tamir. 2016. "Explaining the security paradigm shift: strategic culture, epistemic communities, and Israel's changing national security policy." Defence Studies 16 (2):137 - 56 . 
Libicki, Martin. 2009a. "Sub Rosa Cyber War." In The Virtual Battlefield: Perspectives on Cyber Warfare, edited by Christian Czosseck and Kenneth Geers, 53-65. Washington DC: IOS Press.

Libicki, Martin C. 2009b. Cyberdeterrence and cyberwar. Santa Monica: Rand Corporation.

Liff, Adam P. 2012. "Cyberwar: a new 'absolute weapon'? The proliferation of cyberwarfare capabilities and interstate war." Journal of Strategic Studies 35 (3):401-28.

Lin, Herbert S. 2016. "Attribution of malicious cyber incidents: From soup to nuts."

Lindsay, Jon. 2013. "Stuxnet and the Limits of Cyber Warfare." Security Studies 22 (3):365-404.

Lindsay, Jon R. 2014. "The Impact of China on Cybersecurity Fiction and Friction." International Security 39 (3):7-+.

. 2017. "Restrained by design: the political economy of cybersecurity." Digital Policy, Regulation and Governance.

Manantan, Mark. 2021. "Exploring the cyber factor in the US-Philippines Alliance." In Philippine Strategic Forum.

Maness, Ryan C, and Brandon Valeriano. 2016. "The Impact of Cyber Conflict on International Interactions." Armed Forces \& Society 42 (2):301-23.

Mangosing, Frances. 2021. "PH Air Force building cybersecurity center under deal with tycoon MVP." Inquirer, Accessed

https://newsinfo.inquirer.net/1383378/ph-air-force-building-cybersecuritycenter-under-deal-with-tycoon-mvp.

Maurer, T. 2018. Cyber Mercenaries: The State, Hackers, and Power. New York: Cambridge University Press.

Meyer, Christoph O. 2007. The Quest for a European Strategic Culture: Changing Norms on Security and Defence in the European Union. London: Palgrave Macmillan.

Mirow, Wilhem. 2016. Strategic Culture, Securitisation and the Use of Force. New York: Routledge.

NATO. 2019. "Strategy and Governance." NATO, Accessed 06.12. https://ccdcoe.org/library/strategy-and-governance/.

Nepomuceno, Priam. 2021. "Navy, IT firm ink pact to boost cyber capability." Philippine News Agency, Accessed 15.10. https://www.pna.gov.ph/articles/1108350. . 2021. "PH-US Balikatan exercises to go 'full scale' in 2022." Accessed 18.10. https://www.pna.gov.ph/articles/1156657.

NSC. 2011. "National Security Policy Securing the Gains of Democracy." In, edited by National Security Council. Manila: National Security Council.

2017. "National Security Policy for Change and Wellbeing of the Filipino People." In, edited by National Security Council. Manila: National Security Council.

Parameswaran, Prashanth. 2021. "ASEAN Defense Chiefs Agree to New Cybersecurity Group." The Diplomat, Accessed 16.10. https://thediplomat.com/2016/06/aseandefense-chiefs-agree-to-new-cybersecurity-group/.

Pedrasa, Ira. 2021. "Palace calls for restraint amid cyber attacks between PH, China." ABS-CBN News, Accessed 15.10. https://news.abscbn.com/nation/04/22/12/palace-calls-restraint-amid-cyber-attacks-between-phchina.

Perez-Rubio, Bella. 2021. "Senator flags reported cyber espionage by 'Chinese-speaking actors' ahead of polls." Philippine Star, Accessed 15.10. 
https://www.philstar.com/headlines/2021/07/20/2113850/senator-flags-reportedcyber-espionage-chinese-speaking-actors-ahead-polls.

Perrow, Charles. 1984. Normal accidents : living with high-risk technologies, Princeton paperbacks. Princeton, N.J.: Princeton University Press.

Pettis, Corey. 2021. "Armed Forces of the Philippines, U.S. Military Host Cyber Exchange." United States Navy, Accessed 16.10. https://www.c7f.navy.mil/Media/News/Display/Article/1187034/armed-forcesof-the-philippines-us-military-host-cyber-exchange/.

Posen, Barry. 1986. The sources of military doctrine: France, Britain, and Germany between the world wars: Cornell University Press.

Pytlak, Allison, and George E. Mitchell. 2016. "Power, rivalry, and cyber conflict: an empirical analysis." In Conflict in cyber space : theoretical, strategic and legal perspectives, edited by Karsten Friis and Jens Ringsmose, 65-82. London: Routledge.

Rovner, Joshua. 2019. "Cyber War as an Intelligence Contest." In War on the Rocks. Texas National Security Review.

Saltzman, Ilai. 2013. "Cyber posturing and the offense-defense balance." Contemporary Security Policy 34 (1):40-63.

Schneider, Jacquelyn. 2017. "Cyber and Crisis Escalation: Insights from Wargaming." In.: U.S. Naval War College.

Sechser, Todd S., and Elizabeth N. Saunders. 2010. "The Army You Have: The Determinants of Military Mechanization, 1979-2001." International Studies Quarterly 54 (2):481-511.

Segal, Adam. 2012. "China-Philippines Hacking War: A Missed Opportunity for Beijing?" In Asia Unbound. Council on Foreign Relations.

Shandler, Ryan, Michael L. Gross, and Daphna Canetti. 2021. "A fragile public preference for cyber strikes: Evidence from survey experiments in the United States, United Kingdom, and Israel." Contemporary Security Policy:1-28.

Slayton, Rebecca. 2017. "What Is the Cyber Offense-Defense Balance? Conceptions, Causes, and Assessment." International Security 41 (3):72-109.

Smeets, Max. 2018. "The Strategic Promise of Offensive Cyber Operations." Strategic Studies Quarterly 12 (3):90 - 113.

2020. "U.S. cyber strategy of persistent engagement \& defend forward: implications for the alliance and intelligence collection." Intelligence and National Security 35 (3):444-53.

Snyder, Jack L. 1977. "The Soviet Strategic Culture. Implications for Limited Nuclear Operations." In.: RAND CORP SANTA MONICA CALIF.

Valeriano, Brandon, Benjamin Jensen, and Ryan C. Maness. 2018. Cyber Strategy: The Evolving Character of Power and Coercion. New York: Oxford University Press.

Valeriano, Brandon, and Ryan C. Maness. 2014. "The dynamics of cyber conflict between rival antagonists, 2001-11." Journal of Peace Research 51 (3):347-60.

- 2015. Cyber war versus cyber realities : cyber conflict in the international system. Oxford ; New York: Oxford University Press.

Venzon, Cliff. 2021. "Philippines hoists cyber shield against China Telecom." Nikkei Asia, Accessed 15.10. https://asia.nikkei.com/Business/Companies/Philippineshoists-cyber-shield-against-China-Telecom.

Villacorta, Wilfredo V. 1999. "Philippines: Nationalism and Regionalism." In Strategic Cultures in the Asia-Pacific Region, edited by Ken Booth and Russell Trodd. London: Palgrave Macmillan. 
Wah, Chin Kin. 2000. "Reflections on the Shaping of Strategic Cultures in Southeast Asia." In Southeast Asian Perspectives on Security, edited by Derek de Cunha. Singapore: ISEAS Publishing.

Wallace, Geoffrey. 2008. "Alliances, Institutional Design, and the Determinants of Military Strategy." Conflict Management and Peace Science 25 (3):224-43.

Welch, David A. 2011. Painful choices: a theory of foreign policy change. New Jersey: Princeton University Press.

Whyte, Christopher. 2016. "Ending cyber coercion: Computer network attack, exploitation and the case of North Korea." Comparative Strategy 35 (2):93-102. 